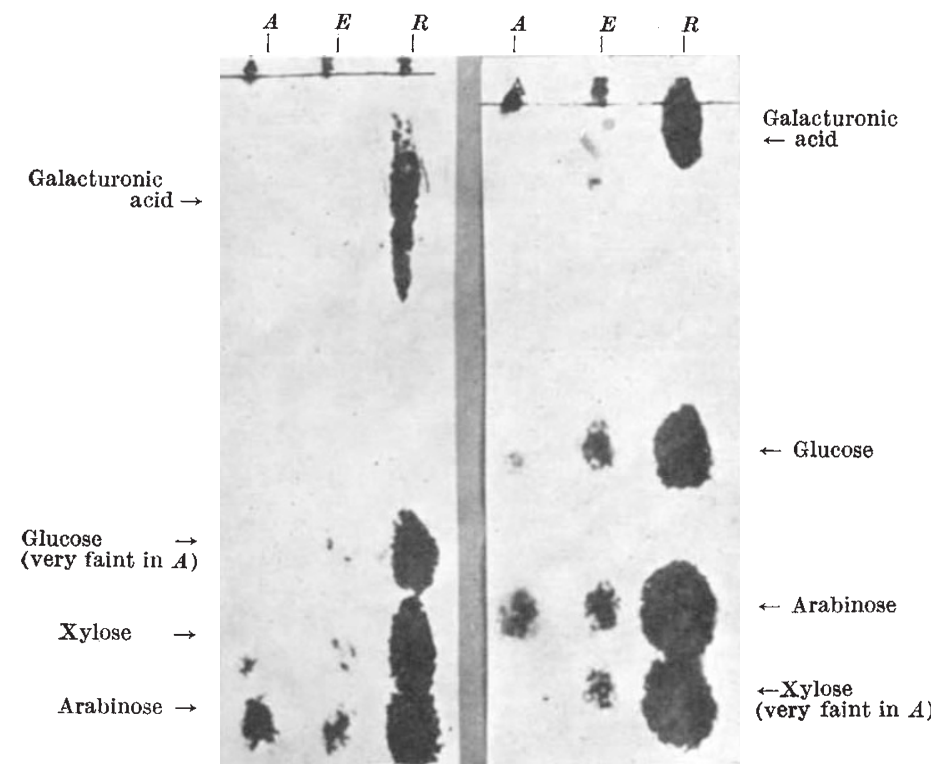

Fig. 1. $A$, American cotton $\alpha$-cellulose; $E$, Egyptian cotton $\alpha$-cellulose; $R$, reference sugars.

Left: Chromatogram in moist phenol for $48 \mathrm{hr}$. in Whatman filter paper No. 1. Right : Chromatogram in moist $n$-butanol for $96 \mathrm{hr}$. in Whatman filter paper

these grounds we feel that the above observations may have far-reaching implications for the accepted structure of cotton $\alpha$-cellulose. The possibility of mixed crystals with these pentoses and glucose cannot be ruled out, and as already noted ${ }^{8}$, it remains to be seen if the new spacing observed recently by Sen and Roy ${ }^{9}$ even in cotton is due to such mixed crystals.

Thanks are due to the Indian Central Cotton Committee and Ahmedabad Textile Industries Research Association for the samples of raw cotton.

D. B. DAS

M. K. Mitra

J. F. WAREHAM

Group Laboratory,

Messrs. Jardine Henderson, Ltd., Calcutta 1. June 8.

${ }^{1}$ Das, Mitra and Wareham, Science and Culture, 18, 249 (1952).

2 Adams and Bishop, Nature, 172, 28 (1953).

3 Das, Mitra and Wareham, Nature, 171, 613 (1953); [174, 228 (1954)].

Adams (private communications, May 1953 and January 1954). "Corey and Gray, cf. Dorée, "Methods of Cellulose Chemistry", 2
(London, Chapman and Hall, 1947).

${ }^{6}$ Das, Choudhuri and Wareham, Science and Culture, 18, 197 (1952).

'Das and Wareham, J. Sci. Int. Res. (India), [13 B, 743 (1954)].

8 Das, paper read at the symposium on "High Polymers" held at the Indian Association for the Cultivation of Science on March 29 , 1954.

'Sen and Roy, Nature, 173, 298 (1954).

\section{Localization of Embryonic Antigens by Antisera labelled with Fluorescent Dyes}

Antrbodies labelled with fluorescent dyes have been used for histochemical localization of antigens in tissue sections by Coons and Kaplan ${ }^{1}$, Marshall ${ }^{2}$ and Hill and Cruickshank ${ }^{3}$. It would seem that this method might be applied to locate tissue antigens during the course of development.

Since the changes in distribution of antigens relative to one another at different stages of development are of interest from the point of view of differentiation, a modification of the method, which enables one to study several antigens simultaneously, has been employed. The use of a mixture of several antisera of different specificities, each coupled to a different dye, makes this possible. It has a further advantage in practice. The antibodies appear to compete to some extent, which has the effect of eliminating some of the minor cross-reactions. Thus a given antiserum will give more restricted localization in combination with another antiserum than by itself.

The colours chosen were green, yellow and red fluorescence ; these were found to be readily distinguished from one another.

The green was due to fluorescein isocyanate, which Dr. R. Smith, of King's College, London, kindly coupled on to a number of samples of antisera. The yellow was 1-dimethyl-amino-5-sulphonylchloride-naphthalene, a sample of which he also provided. The red was nuclear fast red (benzaldehyde-6-nitro-2-sodium-diazotate). All uncombined dye was removed by dialysis. Samples of each antiserum were coupled to each of the three dyes, the specificity and localization remaining the same whatever the colour. The antisera thus treated were against lens and muscle respectively of the mouse, Mus musculus.

The eye of the week-old mouse (which has also been made the subject of a quantitative study by means of radioactive antisera ${ }^{4}$ ) was treated with a mixture of muscle and lens antisera after freezedrying and sectioning in paraffin. Where, for example, the lens serum was dyed red and the muscle green, the following localizations were observed: lens bright red, ciliary process and retina pale pink, epithelium of cornea doubtfully pale pink, extrinsic muscles and suspensory ligament green, choroid pale green. The cross-reactions indicated by the paler colourings may be due either to small quantities of the same or to a similar antigen. Thus the ciliary process, which in Amphibia can regenerate the lens, may actually contain small quantities of lens crystallins or scleroproteins. The choroid and suspensory ligament must contain antigens similar to or identical with some of those in whole muscle.

In the early stages of the embryo mouse, the lens antisera give a diffuse reaction with the brain and $a$ somewhat stronger one with the eye cup and lens vesicle. The highest fluorescence surrounds the eavity of the lens vesicle. There is a cross-reaction of the lens antiserum with the epidermis, which is strongest in the adult.

Thus the use of labelled antibodies may make possible a simple and direct test of insoluble antigens hitherto tested only by indirect methods which may be subject to interfering factors.

A full report will be published elsewhere.

Institute of Animal Genetics,

R. M. Clayton Edinburgh. Aug. 9.

${ }^{1}$ Ccons, A. H., and Kaplan, M. H., J. Exp. Med., 91, 1 (1950).

${ }^{2}$ Marshall, J. M., J. Exp. Med., 94, 21 (1953); Exp. Cell Res., 6, 240 (1954).

${ }^{3}$ Hill, A. G. S., and Cruickshank, B., Brit. J. Exp. Path., 34, 27 - Clayton R. M. and Feldman, M., Experientia (in the press). 